\title{
Aprendizagem Organizacional através de Simulação baseada em Instituições Eletrônicas e Agentes de Software
}

\author{
Giliane Bernardi ${ }^{1,2}$, Antônio Carlos da Rocha Costa $^{1,3}$ \\ ${ }^{1}$ Programa de Pós Graduação em Informática na Educação - PGIE/UFRGS \\ Porto Alegre - RS - Brasil \\ ${ }^{2}$ Centro Universitário Franciscano -UNIFRA - Santa Maria - RS - Brasil \\ ${ }^{3}$ Escola de Informática -UCPEL - Pelotas - RS - Brasil \\ gilianedunifra.br, rocha@atlas.ucpel.tche.br
}

\begin{abstract}
This paper presents the development of an enterprise game to graduate course coordinators training in terms of the learning processes that are under their responsibility. The game was developed using the Electronic Institutions and software agents approach.

Resumo. Este artigo apresenta o desenvolvimento de um jogo de empresa voltado para a capacitação de coordenadores de cursos de graduação no que concerne a aprendizagem dos processos organizacionais que estão sob sua responsabilidade. $O$ jogo foi desenvolvido utilizando a abordagem de Instituições Eletrônicas e agentes de software.
\end{abstract}

\section{Introdução}

As competências gerenciais podem ser entendidas como um conjunto de habilidades e atitudes inerentes ao indivíduo, podendo ser consideradas como um estoque de recursos que o tornam capaz no desempenho das atividades exigidas (McLagan apud Fleury e Fleury, 2004). De acordo com Scott Parry, a competência é resultante, em uma visão simplificada, de três fatores básicos (Parry, 1996): (a) Conhecimentos: compreensão de conceitos e procedimentos (técnicas); (b) Habilidades: representam aptidão e capacidade de realizar e estão associadas à experiência e ao aprimoramento progressivo; e (c) Atitudes: refere-se à postura e ao modo como as pessoas agem e procedem em relação a fatos, objetos e interações com outras pessoas e seu ambiente de trabalho.

Desta forma, torna-se fundamental que as empresas trabalhem com funcionários e/ou equipes que possuam estes três fatores aliados ao seu desempenho profissional, o que pode ser o fator diferencial no mercado. Instituições de ensino podem ser vistas como empresas, no momento em que possuem um quadro de funcionários que executam processos de negócios que precisam ser desenvolvidos adequadamente. No que se refere a Instituições de Educação Superior (IES), a preocupação com a aprendizagem refletese, prioritariamente, na qualidade de ensino apresentada, fator crucial para seu desenvolvimento e sustentabilidade. No entanto, diante das mudanças significativas, associadas ao aumento da competitividade bem como ocorrências freqüentes de alterações nas diretrizes educacionais nacionais, é fundamental que as IES revejam sua missão e seus processos de forma a se adaptarem a essa nova realidade. Neste contexto, 
é importante que a aprendizagem ultrapasse a visão de ensino-aprendizagem apenas ao seu público-alvo, no caso, os alunos, e também se torne prioridade para o quadro de funcionários que compõe sua estrutura organizacional.

Entre os papéis responsáveis pela gestão organizacional de uma IES encontra-se o coordenador de curso de graduação, que exerce uma função de grande relevância para a efetivação de um ensino superior de qualidade. Segundo Silva (2005), isto ocorre pelo fato do coordenador não assumir apenas responsabilidades administrativas, mas também assumir funções com dimensões pedagógicas, acadêmicas e científicas, exigindo dele competências gerenciais, técnicas e científicas no campo profissional correspondente ao curso. No entanto, o que se observa, na maioria dos casos, é que os gestores não apresentam conhecimento aprofundado sobre os processos que estão sob sua responsabilidade, no que se refere ao fluxo de atividades e informações, devido, usualmente, a pouca qualificação ao assumirem cargos administrativos, ocorrendo uma necessidade de profissionalização da gestão. A devida preparação do coordenador para o conhecimento e execução eficiente dos processos administrativos que estão sob sua responsabilidade, com rapidez e precisão, evidentemente terá reflexos positivos no objetivo institucional final, que é a qualidade de ensino de seus alunos.

A utilização de tecnologia de informação pode ser utilizada de várias formas neste contexto, proporcionando treinamento de recursos humanos para conhecimento e execução de suas atividades (Silva, 2002). No que tange à capacitação de recursos humanos na execução e análise de processos organizacionais, Jogos de Empresa informatizados podem ser utilizados como ambientes inovadores e motivadores (Barton apud Casagrande, 2006; Rodrigues e Riscarolli, 2001). Usualmente, o que se observa nas instituições são palestras sobre temas ligados à gestão, mas que não apresentam de forma detalhada a execução de atividades pertencentes à rotina diária dos envolvidos. Além disso, são expositivas e não fazem com que o gestor efetivamente vivencie e reflita sobre os processos.

No que se refere ao aspecto das diversas interações que são necessárias na execução destes processos, conceitos relacionados a agentes de software podem ser utilizados de forma a conseguir representar adequadamente as possíveis interações e como elas ocorrem no desenrolar do processo (Hübner e Sichman, 2007). Uma abordagem que pode ser utilizada para integrar a visão de jogos de empresas e agentes, regulando as interações entre eles, é a de Instituições Eletrônicas (Arcos et al., 2006; Esteva, 2003). O conceito de Instituição Eletrônica é baseado no conceito de instituições humanas, onde o comportamento de agentes é regulado da mesma forma que instituições humanas regulam o comportamento das pessoas (Sabater-Mir et al., 2007). Este artigo apresenta o desenvolvimento do simulador SPOIE - Simulador de Processos Organizacionais baseado em Instituições Eletrônicas, um Jogo de Empresa voltado para o treinamento de processos organizacionais relacionados a coordenadores de cursos de graduação.

\section{Aprendizagem Organizacional e Jogos de Empresa}

Aprendizagem pode ser compreendida como "um processo de mudança de comportamentos a partir da crescente aquisição de conhecimentos sobre si e sobre o meio ambiente" (Vasconcelos e Mascarenhas, 2007). Pensando em termos organizacionais, a aprendizagem implica em conhecer o meio ambiente em que se trabalha, refletir sobre os processos desenvolvidos neste ambiente e promover a 
melhoria do mesmo. Ainda, a aprendizagem permite que a organização se adapte às mudanças internas e externas, disseminando o conhecimento aprendido entre todos os envolvidos.

Entre os diferentes aspectos que podem ser considerados no processo de Aprendizagem Organizacional pode ser citado o conhecimento acerca do fluxo dos processos executados dentro do ambiente organizacional. Segundo Santos (2008), o estudo dos processos de uma organização, de forma sistematizada, pode nortear os caminhos desta organização em direção a inovação e mudança, bem como para novos modelos organizacionais mais leves e flexíveis. Através do mapeamento e representação de processos, é possível obter uma compreensão das atividades executadas em um processo, assim como da inter-relação entre elas e o processo.

Uma das formas de capacitar funcionários de uma organização no conhecimento dos processos aos quais estão relacionados é a simulação dos mesmos, colocando-os frente às atividades e as interações realizadas na execução das mesmas, porém, sem o comprometimento e os custos envolvidos na prática real. Jogos podem ser utilizados para realizar um treinamento de forma motivadora, simulando situações reais de maneira mais lúdica e pedagógica. Entre as modalidades de jogos com objetivo educacional, encontram-se os Jogos de Empresa, que tem como finalidade simular situações organizacionais por meio de interfaces mais agradáveis e com maior potencial pedagógico. A próxima seção apresenta este tema, abordando possibilidades da utilização de Jogos de Empresa para Aprendizagem Organizacional, na simulação de processos organizacionais.

\subsection{Jogos de Empresa}

De acordo com Tarouco et al. (2004), os jogos fazem parte do cotidiano das pessoas há muito tempo, desde a infância até a fase adulta, sendo que os mesmos podem ser vistos como ferramentas instrucionais eficientes, pois divertem, motivam e, desta forma, facilitam o aprendizado e aumentam a capacidade de retenção do que foi ensinado. Ainda, permitem o reconhecimento e entendimento de regras, identificação dos contextos em que estão sendo utilizadas e abstração de novos contextos para a modificação das mesmas. Considerando os modelos de processos de negócio, as regras podem ser consideradas o próprio modelo e sua forma de execução, o contexto está inserido nos objetivos do processo e na movimentação lúdica proporcionada por um jogador em um jogo computacional e os novos contextos estão relacionados com as novas proposições obtidas através da simulação que permitirão modificações e melhorias nos processos simulados. Entre as modalidades de jogos com caráter instrucional, destacam-se os Jogos de Empresa.

A principal característica dos Jogos de Empresa informatizados é que eles são conduzidos, usualmente, como uma simulação de processos. Naylor apud Freitas (2002) realça que Jogos de Empresa podem ser considerados uma "simulação na qual pessoas participam ativamente como tomadores de decisões dentro de um sistema organizacional que está sendo simulado". Assim, é possível considerar que os Jogos de Empresa representam um método educacional cuja principal característica é prover uma dinâmica vivencial que guarda grande semelhança com o que ocorre no dia-a-dia de uma organização. Sauaia (2006) destaca que os Jogos de Empresa, através do envolvimento dos jogadores, com suas experiências e valores, permitem um conhecimento mais pleno, à medida que eles não são mais meramente receptáculos de 
informações. Para o autor, o aumento de conhecimentos ocorre quando os participantes incorporam novas informações disponibilizadas pelos jogos.

No que tange a educação de recursos humanos na execução e análise de processos organizacionais, Jogos de Empresa informatizados podem ser utilizados como ambientes inovadores e motivadores. Através da execução de um Jogo de Empresa é possível desenvolver habilidades, ampliar conhecimentos e identificar soluções inteligentes, fatores cruciais para o desenvolvimento de competências empresariais. Considerando os jogos de empresa como mecanismos de aprendizagem dos processos de negócio, pode-se observar que mesmo as rotinas do dia-a-dia passam a fazer mais sentido quando inseridas em um contexto maior, da organização como um todo. Usualmente, as pessoas detêm em suas memórias as tarefas que lhe cabem, não tendo uma visão do todo e, por vezes, não compreendendo a razão de suas tarefas. Através dos Jogos de Empresa é possível simular todo o processo de negócio organizacional inserindo as tarefas de um funcionário em específico, que pode "jogar" simulando suas atividades.

Após analisar o cenário apresentado, pode-se visualizar o coordenador de curso atuando como um jogador na simulação de suas tarefas. Considerando os objetivos este trabalho, pode-se inferir que os Jogos de Empresa se apresentam como uma ferramenta adequada para o treinamento dos processos organizacionais de um coordenador de curso em uma instituição de ensino. A próxima seção apresenta as Instituições Eletrônicas, abordagem utilizada para o desenvolvimento do jogo proposto.

\section{Instituições Eletrônicas}

Segundo Sabater-Mir et al. (2007), os indivíduos, no dia-a-dia, interagem com diversas pessoas para alcançar seus objetivos, sendo que muitas destas interações são reguladas pelo que os autores chamam de instituições, que têm como objetivo verificar se normas e protocolos estão sendo seguidos de forma correta durante tais interações. Instituições podem ser consideradas, neste contexto, como representações que estabelecem toda e qualquer restrição (formal ou informal) que indivíduos devem seguir durante as interações.

O conceito de Instituição Eletrônica (IE) é baseado no conceito de instituições humanas, onde as mesmas atuam "regulando" o comportamento de agentes da mesma forma que instituições humanas regulam o comportamento das pessoas. O modelo de uma instituição eletrônica é composto de alguns elementos básicos (Arcos et al., 2006):

- Agentes e Papéis: agentes são considerados jogadores em uma instituição eletrônica, interagindo através de atos de fala. No caso de um jogo para gestores, visualizam-se os agentes "coordenador" de curso, demais "órgãos administrativos", alunos", entre outros, interagindo em diferentes papéis;

- Framework Dialógico: representa o contexto das interações entre os agentes, que ocorrem através de atos de fala, utilizando um dicionário (ontologia) bem definido e uma linguagem comum;

- Cenas: as interações entre agentes ocorrem por meio de reuniões, chamadas cenas, sendo que tais interações são definidas através de protocolos de comunicação, que representam todos os diálogos que os agentes podem ter em cada cena; 
- Estrutura Performativa: relação entre cenas, compondo uma rede de cenas. Cada processo administrativo pode ser representado por uma estrutura delineada por cenas; e

- Regras Normativas: as regras definem o contexto e as possíveis conseqüências de determinadas ações. No estudo de caso em questão, podem ser estabelecidas regras institucionais e diretrizes nacionais.

Em (Esteva, 2003) é apresentado um ambiente para desenvolvimento baseado em Instituições Eletrônicas, denominado EIDE (Electronic Institutions Development Environment). O ambiente é formado pelas seguintes ferramentas: (a) Islander: ferramenta gráfica que suporta a especificação e verificação estática das regras da instituição; (b) Simdei: ferramenta de simulação para animar e analisar as especificações criadas na Islander. Corresponde a uma verificação dinâmica das especificações geradas; (c) aBuilder: ferramenta de desenvolvimento de agentes que, de acordo com a especificação de uma instituição eletrônica feita via Islander, gera a estrutura (esqueleto) dos agentes envolvidos. Esta estrutura pode ser usada pelas simulações da Simdei, bem como pela execução da instituição via Ameli; e (d) Ameli: plataforma de software para executar a aplicação especificada via Islander. Ainda, é possível utilizar uma ferramenta de monitoramento das execuções de instituições eletrônicas que estão sendo executadas pela Ameli. O próximo capítulo apresenta o desenvolvimento do jogo SPOIE utilizando a abordagem de Instituições Eletrônicas e o ambiente EIDE.

\section{O Jogo SPOIE}

O sistema SPOIE - Simulador de Processos Organizacionais baseado em Instituições Eletrônicas foi desenvolvido com o objetivo de proporcionar aos coordenadores de cursos de graduação uma base comum para realizar o treinamento de processos administrativos. Como apresentado anteriormente, simular ambientes reais, colocando o aprendiz frente às atividades e as interações realizadas na execução das mesmas, é uma prática interessante que pode proporcionar uma aprendizagem mais significativa. As experiências vivenciais de um ambiente simulado proporcionam uma visão mais rica da realidade do que a simples exposição de fluxogramas de atividades. Os processos implementados no SPOIE foram definidos com base em uma Universidade Comunitária da região central do Rio Grande do Sul. Foram construídos seis processos, sendo que os mesmos foram modelados conceitualmente e, posteriormente, foram especificados dentro do âmbito de uma Instituição Eletrônica.

A formalização do SPOIE foi realizada em duas etapas. A primeira etapa envolveu a coleta de dados na Universidade Comunitária analisada. Durante esta etapa, foram consultados documentos institucionais e entrevistados coordenadores de curso para estabelecer os processos, atividades e os documentos que são gerados e/ou são necessários para a realização dos mesmos. Esta formalização foi de fundamental importância para o entendimento dos processos como um todo. Após a formalização dos processos, foi desenvolvida a especificação da Instituição Eletrônica através do ambiente EIDE. As próximas seções apresentam a modelagem e o desenvolvimento do jogo. 


\subsection{A Modelagem}

A figura 01 apresenta a estrutura performativa, desenvolvida na ferramenta Islander, para o processo de Alteração da Matriz Curricular.

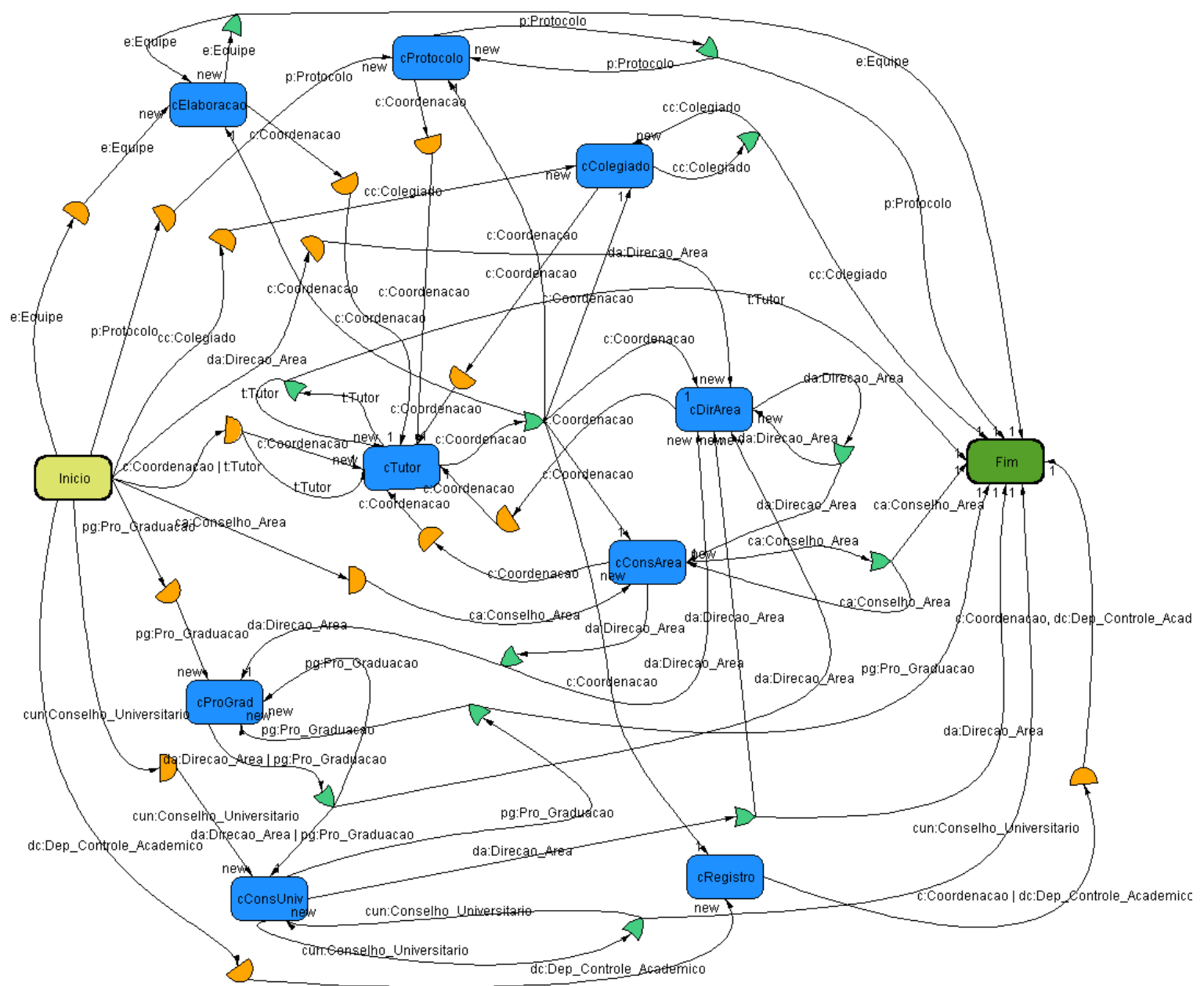

Figura 1. Especificação do processo de Alteração da Matriz Curricular

A alteração da matriz curricular é uma atividade que ocorre esporadicamente, mas de grande complexidade para o gestor na coordenação. As seguintes atividades são executadas para a realização deste processo: (1) montagem da nova grade curricular envolvendo uma Equipe de professores designada pela coordenação, juntamente com o próprio Coordenador; (2) abertura do processo interno para alteração curricular no Protocolo; (3) encaminhamento da proposta de alteração ao Colegiado; (4) avaliação da proposta de alteração pelo Colegiado; (5) se a proposta é aprovada, a mesma deve ser encaminhada, juntamente com a ata de aprovação, para a Direção de Área; (6) a Direção de Área analisa a proposta e, mediante ofício com parecer, encaminha para o Conselho de Área; (7) o Conselho de Área delibera sobre a proposta e a envia para a Pró-Reitoria de Graduação, anexando a ata ao processo; (8) a Pró-Reitoria de Graduação anexa parecer ao processo e encaminha ao Conselho Universitário; (9) o Conselho Universitário delibera sobre a proposta e encaminha, juntamente com seu parecer, para o coordenador, que concretiza a alteração curricular junto ao Departamento de Controle 
acadêmico; e (10) caso a proposta não seja aprovada em algum órgão, o processo retorna à coordenação do curso que avalia o relatório de forma a adotar as mudanças necessárias em conjunto com sua equipe. O fluxo, neste caso, reinicia a partir da primeira atividade.

Este processo envolve os seguintes papéis: Coordenação, Tutor, Equipe, Protocolo, Colegiado, Direção de Área, Conselho de Área, Pró-Reitoria de Graduação, Conselho Universitário e Departamento de Controle Acadêmico. Conforme é possível perceber na figura 01, há um papel adicional modelado no SPOIE, denominado Tutor. A concepção do modelo de agentes no simulador está centrada fortemente na presença do agente Tutor. Este agente é o único que não foi definido no modelo dos processos, pois o mesmo é específico da simulação. A idéia central da utilização de um Tutor é que ele seja utilizado como uma espécie de barreira entre o agente Coordenação e os demais agentes. A modelagem de uma Instituição Eletrônica prevê que a engenharia de software seja desenvolvida a partir das regras da organização, ou seja, só é possível trocar mensagens e seguir os caminhos entre as cenas que estão previamente configuradas.

No entanto, para o desenvolvimento de uma simulação de processos, muito mais do que indicar os caminhos corretos, o principal objetivo da experiência vivencial é a possibilidade exploratória que um jogo deste tipo permite. Ou seja, a possibilidade dos coordenadores poderem se movimentar livremente pelo ambiente, interagindo com os diversos agentes e percorrendo caminhos potencialmente errados é que torna a experiência mais rica para o utilizador. Caso contrário, a simulação seria um pouco mais do que um fluxo animado.

Desta forma, foi concebido o desenvolvimento de um agente Tutor que permeia todas as ligações entre o coordenador e os demais agentes. O agente Coordenação sempre, em todas as situações, deve se dirigir, primeiramente, ao agente Tutor. Este, por sua vez, mantém em sua base de conhecimento interno a situação da Coordenação em relação ao processo que está sendo modelado. A troca de mensagens entre os dois agentes ocorre com o intuito do agente Coordenação perguntar ao Tutor se ele pode seguir um determinado caminho, ou seja, interagir com um agente da instituição. $O$ Tutor, por sua vez, deve consultar sua base de conhecimento e, conhecendo o modelo do processo, decidir se o caminho que a Coordenação deseja seguir é o correto ou não. Em caso positivo, o agente Coordenação sai da cena do Tutor e desloca-se até a cena específica. Caso contrário, o Tutor nega o caminhamento para a Coordenação que, por sua vez, permanece dentro da cena do tutor até que escolha o caminho correto.

A estrutura performativa par o processo de alteração Curricular conta com uma cena inicial, uma cena final e nove cenas intermediárias. Para cada cena, é definido um grafo de estados, contendo as possíveis interações entre os agentes participantes da mesma. A figura 02 apresenta o grafo de estados da cena de Análise do Colegiado.

Todo gráfico possui um estado inicial (neste caso, E1) e um ou mais estados finais (neste caso, E3). As setas representam as transições de um estado para outro, onde as interações ocorrem através do framework dialógico. Neste caso, três interações estão sendo representadas. Na primeira delas (1), o papel Coordenação pergunta ao papel Colegiado_Curso se ele aprova a Alteração Curricular e passa-se para o estado E2 onde o Colegiado_Curso fará a análise da proposta. Duas possibilidade podem ocorrer, a partir do estado E2: o Colegiado_Curso pode aprovar a proposta e ocorre a interação 2, onde Colegiado_Curso informa à Coordenação que aceita a proposta; ou 
Colegiado_Curso pode rejeitar a proposta e ocorre a interação 3, onde Colegiado_Curso informa à Coordenação que rejeita a proposta. Independente da interação que ocorra no estado E2, passa-se para o estado E3 (estado final) e os agentes saem da cena.

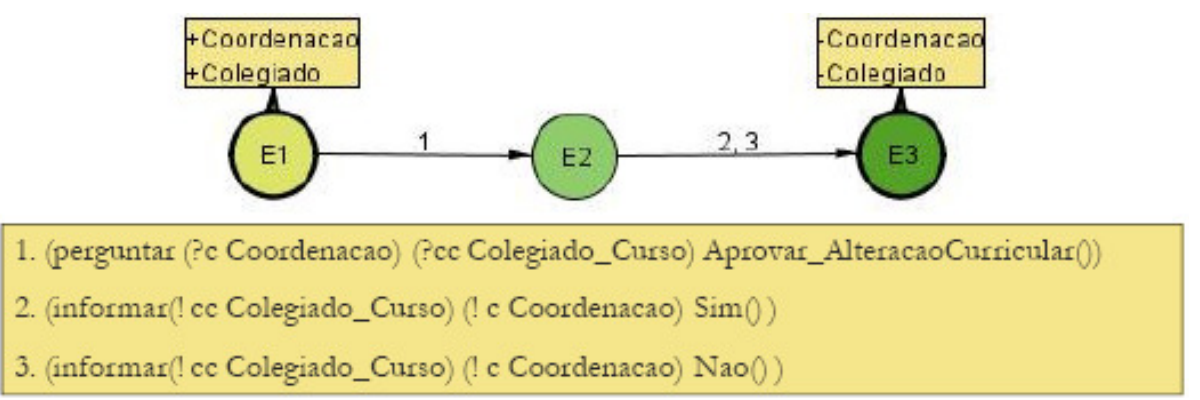

Figura 2. Grafo de estados da cena cColegiado

Após a realização da modelagem da estrutura performativa dos processos, é possível modelar cada agente envolvido nas interações. Como visto anteriormente, isto pode ser feito através da ferramenta aBuilder. Nela, para cada agente envolvido na estrutura, são definidas suas atividades, bem como todos os seus caminhamentos pela estrutura, desde o estado inicial (quando entra na estrutura), até o estado final (quando sai da estrutura e o processo encerra). A ferramenta aBuilder gera uma estrutura de código (esqueleto) para cada agente, na linguagem Java. A partir deste ponto, todo o comportamento de cada agente, em cada cena, teve que ser implementado. Com a modelagem da estrutura e implementação dos agentes concluída, é possível executar a aplicação e verificar seu comportamento através da ferramenta de monitoramento Ameli.

No entanto, para que a simulação possa ser executada de forma mais lúdica, é fundamental que uma interface mais adequada seja criada. Desta forma, foi desenvolvida uma interface (o jogo propriamente dito), que faz a "leitura" das especificações geradas pelo EIDE, sendo monitorado pela ferramenta Ameli. O mesmo foi desenvolvido utilizando o framework de desenvolvimento JavaGame (http://javagamelibrary. sourceforge.net).

\subsection{Interface e Arquitetura do SPOIE}

Ao acessar a interface principal do SPOIE, o usuário pode escolher qualquer um dos processos disponíveis. Para cada processo, o usuário pode escolher visualizar o fluxo de documentos, o fluxo de atividades ou simular o processo. O fluxo de atividades representa, de forma gráfica, o fluxograma de passos, na ordem em que devem ocorrer, do processo que está sendo apresentado. Este modelo pode ser utilizado pelo jogador para obter uma visualização completa do processo em questão, na forma estática. Nele, são apresentados os passos que devem ser executados e as decisões que podem ser tomadas pelos papéis envolvidos no processo. O modelo de fluxo de documentos apresenta uma visão simplificada do fluxo de atividades, descrevendo os documentos necessários e/ou produzidos em cada atividade. Este modelo busca apresentar ao coordenador uma visão geral de todos os documentos que tramitam na execução de um processo. 
Quando o usuário escolhe simular o processo, três ações são realizadas pelo SPOIE: (a) execução da ferramenta Ameli: este sistema realiza a leitura da especificação da Instituição Eletrônica com o objetivo de regular as regras estabelecidas para os processos da instituição. Os agentes que serão instanciados a seguir têm seus comportamentos e diálogos monitorados pela ferramenta; (b) instanciação dos agentes da instituição: os agentes que atuarão na instituição devem ser instanciados e conectados à Ameli para que possam iniciar suas atividades nas estruturas performativas definidas na Instituição Eletrônica; e (c) execução da simulação: a interface de simulação é carregada e os atores que personificarão os agentes da instituição são instanciados, bem como os objetos animados. A interface de simulação representa o jogo propriamente dito. A figura 03 apresenta a arquitetura de simulação de um processo dentro do jogo SPOIE.

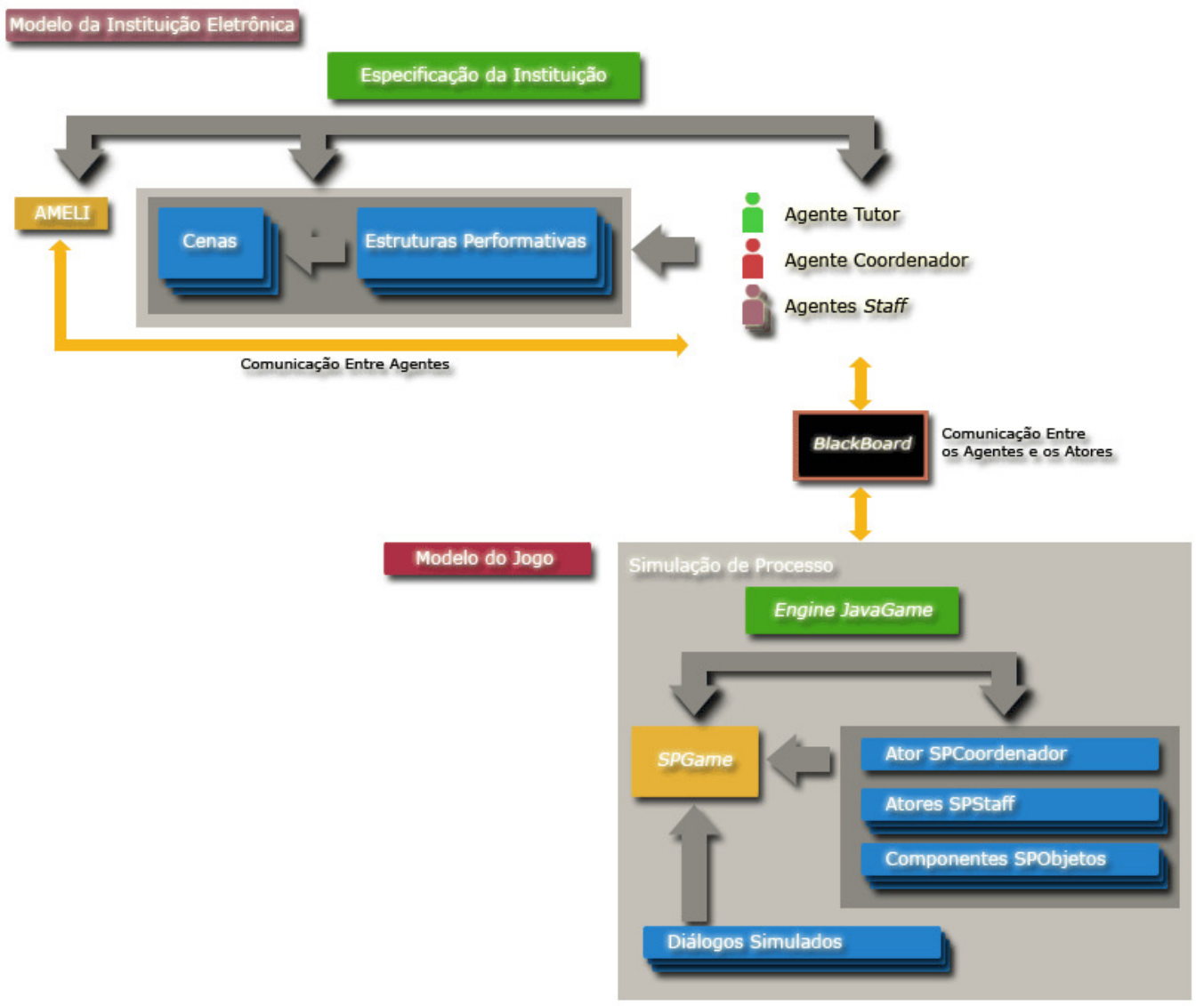

Figura 3. Arquitetura do jogo SPOIE

A arquitetura do SPOIE é dividida em dois modelos: a) o Modelo da Instituição Eletrônica, onde as estruturas performativas, as cenas e os agentes foram construídos utilizando-se das ferramentas Islander e aBuilder; e b) o Modelo do Jogo, onde são modelados e implementados os componentes do jogo propriamente dito. Cada Simulação de Processo no SPOIE é concebida, conceitualmente, como uma representação animada dos processos de negócio que foram definidos nas estruturas performativas da Instituição Eletrônica. Para fins didáticos, os agentes desenvolvidos neste modelo são denominados atores, por representarem uma função mais próxima da realidade do cenário simulado. Neste jogo, o coordenador, usuário do sistema, assume o papel de um ator animado que deve se deslocar pelo ambiente com o intuito de conversar com os demais atores do jogo. A intenção é que o coordenador reconheça seu 
papel na hierarquia da instituição e, de forma mais decisiva, compreenda como os processos organizacionais são definidos e executados dentro da instituição modelada.

Existem dois tipos de atores definidos no SPOIE: o ator que representa o coordenador (SPCoordenador) e é controlado manualmente por este; e os atores da instituição (SPStaff), que representam os demais funcionários da organização, representados por agentes de software, com representação autônoma. Um exemplo de um cenário simulado se encontra na figura 04.

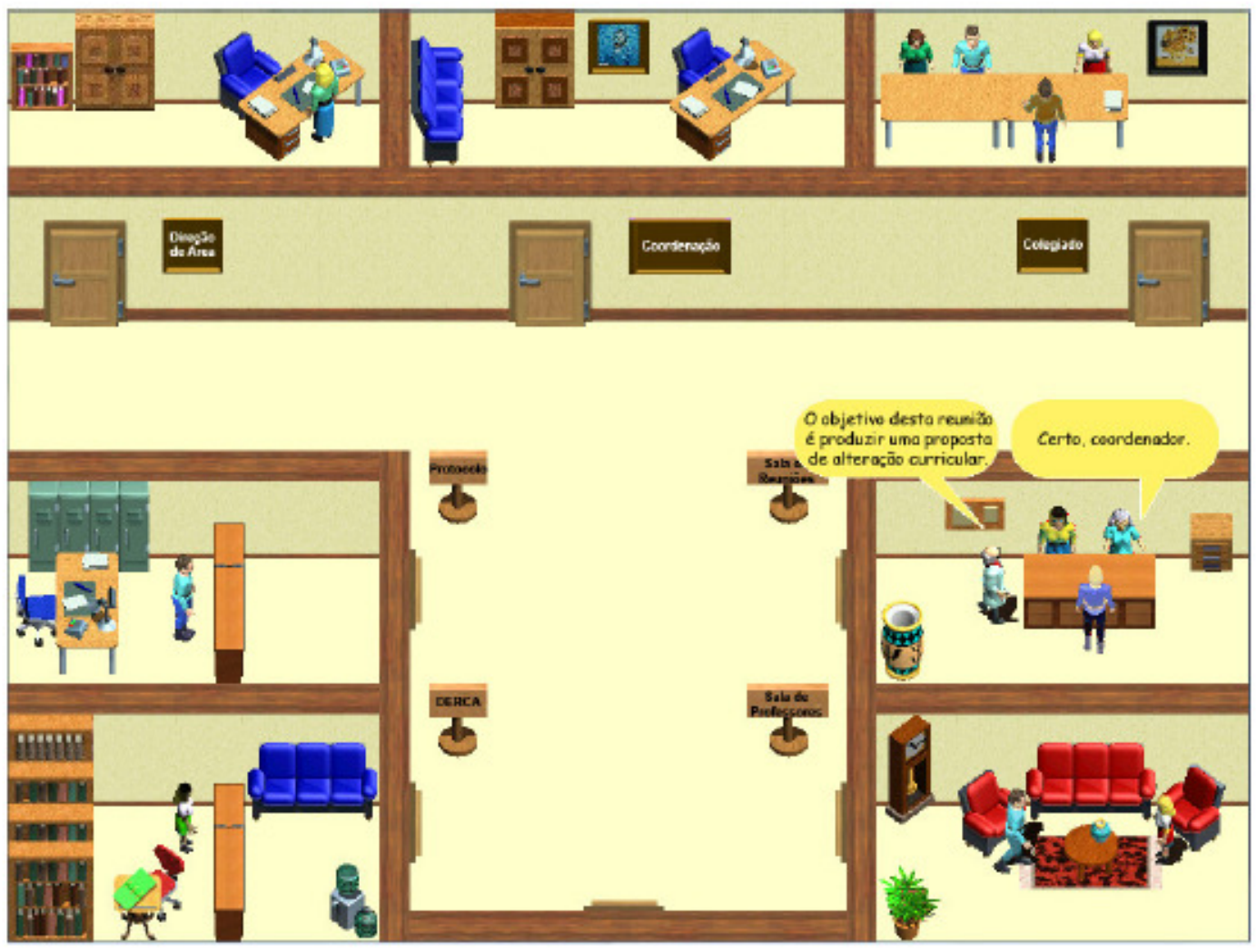

Figura 4. Cenário simulado no SPOIE

\section{Conclusões}

Este estudo buscou na Aprendizagem Organizacional uma forma de prover treinamento aos coordenadores de cursos de graduação, principalmente no que concerne ao conhecimento dos processos administrativos que estão sob sua responsabilidade, permitindo que trabalhassem a habilidade de realizá-los para que a sua atitude e postura na instituição pudessem se modificar a partir deste treinamento.

Buscando apoio nos Jogos de Empresa como forma de promoção deste treinamento, o objetivo principal deste trabalho foi desenvolver um simulador que pudesse ser aplicado aos coordenadores de curso com intuito de treiná-los em seus processos administrativos. A escolha desta metodologia deveu-se ao seu caráter inovador, dinâmico, interativo e lúdico, além de ter como característica central de sua utilização o desenvolvimento pessoal dentro de um contexto empresarial. Para promover as interações necessárias ao Jogo de Empresa, foi realizado um estudo sobre agentes de software e sua utilização em Instituições Eletrônicas, uma abordagem que permite a implementação de organizações de agentes que interagem para atingir um 
objetivo global através de regras normativas bem definidas. A utilização de uma abordagem orientada a agentes de software, modelando todos os envolvidos e as interações entre eles através da abordagem de Instituições Eletrônicas possibilita uma maior flexibilidade no que se refere ao mapeamento do comportamento associado a cada agente, podendo realizar modificações nas interações trocadas, criando novas possibilidades ao coordenador. A importância das Instituiçõoes Eletrônicas para este trabalho se deve a analogia com as organizações humanas, característica que está no cerne do seu desenvolvimento.

Os estudos realizados formaram a base para a implementação do jogo SPOIE Simulador de Processos Organizacionais baseado em Instituições Eletrônicas. Após a implementação do SPOIE foi realizada uma experiência de utilização do mesmo com coordenadores de graduação de três instituições. As principais observações realizadas são descritas a seguir: (a) o treinamento dos processos é considerado um dos benefícios mais citados pelos utilizadores, o que pode inferir que o jogo atingiu seus objetivos; (b) o simulador, de forma geral, foi considerado como a forma de treinamento mais indicada para a aprendizagem dos processos em relação a explanação estática dos mesmos; e (c) o SPOIE desafiava os seus participantes, atraindo os mesmos para a realização de todas as etapas.

Conclui-se que o treinamento dos processos administrativos pode auxiliar no conhecimento, de forma detalhada, do fluxo de atividades e informações e como elas devem ser percorridas e desenvolvidas no decorrer dos processos. Com este conhecimento apreendido, espera-se que os coordenadores possam refletir sobre os mesmos, buscando alternativas que otimizem o tempo de desenvolvimento de suas tarefas, bem como aperfeiçoem sua execução. Refletindo sobre suas atividades, os processos podem ser melhorados e adaptados para novas situações, de forma a permitir a melhoria constante na sua realização.

Como trabalhos futuros, pretende-se: (a) estender o modelo, inserindo novos processos aos já especificados; (b) analisar a possibilidade de inserir outros agentes humanos, além do coordenador, ao jogo, permitindo uma aprendizagem cooperativa por parte da organização; (c) utilizar-se dos preceitos da computação afetiva para modelar e implementar um agente pedagógico animado que acompanhe os participantes no decorrer da simulação; (d) estender o modelo a outros setores organizacionais, tais como diretores de área, pró-reitores e chefes de departamento; (e) inserir a possibilidade de simulação da construção dos documentos necessários a cada processo; (f) atualizar a interface para um modo tridimensional com o intuito de melhorar a sensação de imersão do coordenador em seu mundo virtual. Alguns trabalhos de integração de Instituições Eletrônicas e ambientes tridimensionais têm sido publicados (Seidel e Berger, 2007) (Smith e Maher, 2007).

\section{Referências Bibliográficas}

Arcos, J. L.; Esteva, M.; Noriega, P.; Rodrígues-Aguilar, J. A.; Sieera, C. (2006) "Na Integrated Development Environment for Electronic Institutions". In: Software Agent- Based Applications, Platforms and Development Kits.

Casagrande, M. D. H. (2006) "Jogo de Empresa na Prática de Ensino de Contabilidade Tributária”. Tese (Doutorado) - Programa de Pós-Graduação em Engenharia de Produção, Universidade Federal de Santa Catarina, UFSC, Florianópolis. 
Esteva, M. (2003) "Electronic Institutions: from specification to development". Tese (Doutorado) - Artificial Intelligence Research Institute, IIIA, Espanha.

Fleury, A.; Fleury, M. T. L. (2004) "Estratégias Empresariais e Formação de Competências: um quebra-cabeça caleidoscópico da indústria brasileira". São Paulo: Atlas.

Freitas, S. C. (2002) "Adaptação de um Jogo de Empresas para o Ensino de Análise de Investimentos". Dissertação (Mestrado) - Programa de Pós-Graduação em Engenharia de Produção, Universidade Federal de Santa Catarina, UFSC.

Hübner, J. F.; Sichman, J. S. (2007) “Organização em Sistemas Multiagentes”. In: WESAAC 2007, Worshop-Escola de Sistemas de Agentes para Ambientes Colaborativos, Pelotas, RS.

Parry, S.B. (1996) "The Quest for Competencies". Training.

Rodrigues, L. C.; Riscarolli, V. (2001) "O Valor Pedagógico dos Jogos de Empresa". In: Encontro Nacional dos Cursos de Graduação em Administração, XII, São Paulo. Disponível em: http://www.angrad.org.br/cientifica/artigos/artigos_enangrad/ enangrad_12. asp. Acesso em jun. 2008.

Sabater-Mir, J., Pinyol, I., Villatoro, D., Cuni, G., Sierra C., Rodriguez-Aguilar, J. A. and Arcos, J. L. (2007) "e-Institutions oriented to the use of Reputation". Sixth Framework Programme Priority 7. Bellaterra, Catalonia, Spain.

Santos, G. K. (2008) "Mapeamento de processos e aprendizagem organizacional." Monografia (Especialização em Gestão de Projetos em Fundações de Apoio) Universidade Federal de Minas Gerais - UFMG, Belo Horizonte.

Sauaia, A. C. A. (2006) 'Conhecimento Versus Desempenho das Organizações: um estudo empírico com jogos de empresas". REAd - Revista Eletrônica de Administração, UFRGS, Porto Alegre.

Seidel, Ingo; Berger, Helmut. (2007) "Integrating Electronic Institutions with 3D Virtual Worlds”. In: IEEE/WIC/ACM International Conference on Intelligente Agent Technology.

Silva, M. G. R. (2005) "Coach e Papéis Gerenciais” In: RUAS, R. et al. (Org.) Os novos horizontes da gestão: aprendizagem organizacional e competências. Porto Alegre: Bookman, cap. 2, p. 116-131.

Silva, D. R. (2002) "Educação Corporativa". In: Revista Estudante On-Line. Fundação Escola de Comércio Álvares Penteado,Bahia.

Smith, Greg; Maher, Mary Lou. (2007) 'Designing Virtual Worlds for 3D Electronic Institutions". In: CAAD Futures, Springer.

Tarouco, L. M. R.; Roland, L. C.; Fabre, M. J. M.; Konrath, M. L. P. (2004) "Jogos Educacionais". RENOTE - Revista de Novas Tecnologias na Educação, PGIE, UFRGS, Porto Alegre.

Vasconcelos, I. F. G. e Mascarenhas, A. O. (2007) "Organizações em aprendizagem”.Thomson Learning (Coleção Debates em Administração). 